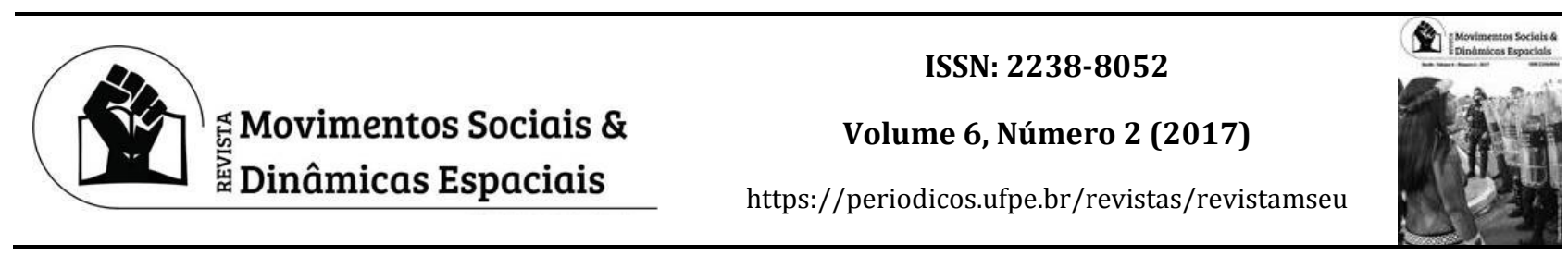

\title{
ENTREVISTA COM SUZANNE DAVEAU
}

\author{
INTERVIEW WITH SUZANNE DAVEAU
}

\author{
Katielle Susane do Nascimento SILVA ${ }^{1}$ \\ Jorge Silva Macaísta MALHEIROS²
}

\begin{abstract}
R E S U M O
Suzanne Daveau, nascida em França, com um percurso profissional no seu país de nascimento, no Senegal e em Portugal, escolheu este último país, pelo coração, para trabalhar e viver. Aqui, ela nos presenteia com uma entrevista realizada no dia 06 de junho de 2017, em sua residência em Vale de Lobos, concelho de Sintra, Portugal, no auge dos seus 92 anos de vida. A conversa aconteceu em sua sala de estar, no meio de centenas de livros e fotografias de familiares e de trabalho de campo, que a Professora, com um prazer imenso, explica quando foram registradas, em que contexto, de que falavam naquela altura, quase como se estivesse a dar uma aula e permitindo-nos viajar junto com ela. Entre as suas paixões estão a geografia, a fotografia e...gatos. A paixão pela geografia surgiu a partir do contato com "o que era a geografia" já na Universidade, quando no único dia de folga da escola primária onde era Professora, as quintas-feiras, pôde frequentar aulas na Universidade, durante o período em que se ensinava geografia. E o encantamento com a geografia tornou-se ainda maior com a descoberta de que essa ciência é ainda mais interessante quando saímos dos gabinetes e a fazemos no campo. Já a paixão pela fotografia parece ter ultrapassado gerações, sendo uma herança do avô materno e da mãe. E os gatos têm sido sua companhia por muitos anos. Na entrevista abaixo, conhecerão um pouco da inspiradora e rica trajectória pessoal e profissional da Geógrafa e Professora Suzanne Daveau, que me encantou profundamente. Na verdade, mesmo de longe e através de seus escritos, eu (Katielle Silva) ainda enquanto aluna do primeiro semestre da graduação em geografia, tive a primeira oportunidade de conhecer e admirar o seu trabalho. Contudo, foi após ter ouvido suas palavras de incentivo e força, visto os seus olhos atentos e esperançosos e compartilhado de seus conhecimentos e de suas memórias tão ricas, ainda fiquei mais impressionada e apaixonada pelo que fez e pelo significa, esta notável "mulher da ciência geográfica". É isto que agora nós partilhamos convosco, tornando colectiva a experiência por que passamos, de modo que possamos enriquecernos com ela. Para finalizar, queremos deixar "um muito obrigado" à Professora Suzanne Daveau pela entrevista e muito do seu tempo.
\end{abstract}

\footnotetext{
1 Doutoranda em Geografia Humana no Instituto de Geografia e Ordenamento do Território (IGOT) da Universidade de Lisboa. Investigadora associada do Centro de Estudos Geográficos, ULisboa e dos Grupos de Pesquisa Movimentos Sociais e Dinâmicas Espaciais (MSEU) e Dinâmicas e Políticas Urbanas e Regionais (ZOE). E-mail: katielle@campus.ul.pt.

2 Professor Doutor do Instituto de Geografia e Ordenamento do Território da Universidade de Lisboa, investigador do Centro de Estudos geográficos e Coordenador o ZOE (Grupo de Pesquisa Dinâmicas e Políticas Urbanas e Regionais). E-mail: jmalheiros@campus.ul.pt.
} 


\begin{abstract}
A B S T R A C T
Suzanne Daveau was born in France in 1925 and her career as a geographer passed through France (her home country), Senegal and Portugal. She chose to live in the latter by love. In this interview, done on June 6th 2017, she offers us her wisdom at the wonderful age of 92 . We held this talk in her living room, amongst hundreds of books, family pictures and fieldwork materials, the circumstances of which are explained to us by her, as if she were back to teaching, allowing us to travel back in time with her.

Her lifelong passions include geography, photography and... cats. Her passion for geography came by through a happy coincidence. In her early professional years as a primary teacher, the only day off she had to attend courses at university was on Thursdays, and these were the days of geography courses. Her enchantment with the science grew with the discovery that geography is even more interesting when one leaves the office and goes into fieldwork. Her passion for photography comes as if an inheritance from her grandfather and her mother, who already practiced it. And cats have been her good companions for many years. In this interview the reader will be able to learn about her inspiring and rich trajectory, both professional and personal.

I, Katielle Silva, was first introduced to her work while a graduation student, during the first semester of my degree in geography. However, it was only after listening in person to her words of strength and incentive, to have stared into her attentive and hopeful eyes, and to see her share her knowledge and rich memories that I became truly passionate about the meaning of her work, that of a notable "woman of the geographic science". We wish to share this interview with the readers in the hope it will enrich others as it has enriched us. Finally, we want to thank Professor Suzanne Daveau for her kindness in giving us the interview and a lot of her time.
\end{abstract}

Katielle Silva/Jorge Malheiros: A senhora já deve ter respondido muitas vezes a essa pergunta, mas não posso deixar de fazê-la: o que a levou à escolha da geografia como ciência e profissão?

Suzanne Daveau: De uma certa medida, dê-me um instante, deixe-me pensar um bocadinho. Bom, quando eu era jovem, gostei muito de estudar e a minha finalidade era me tornar Professora do Ensino Primário. Eu era de uma família do povo, um pouco acima do povo, droguistas e comerciantes, assim de um bairro popular e eu como gostava de estudar, queria imitar as senhoras que me ensinavam e tornar-me uma Professora do Ensino Primário. De maneira que eu estudei para isto e passei em um concurso para entrar na Escola que preparava os Professores para o Ensino Primário. Mas chegou a Guerra, a França foi derrotada e ocupada pelos Alemães, vigorando então um Governo de Direita, chamado Governo de Vichy (da pequena cidade termal onde se instalou). Este Governo fechou as Escolas de Formação dos Professores de Ensino Primário, que considerava como sendo núcleos de formação de Comunistas. Como consequência, eles nos mandaram para o Liceu, o que em certa medida me abriu os horizontes, especialmente porque o nosso grupo de raparigas era de muito bom nível (nessa altura, eram rapazes de um lado e raparigas do outro), e os Professores gostavam muito de nos ensinar, porque éramos interessadas, obedientes, e o resultado foi que não só eu, mas muitas tiveram vontade de continuar a estudar para além da Formação de Professores. E nessa altura eu hesitava em ir para as ciências naturais ou para a geografia. Vivíamos na cidade, mas os meus pais, especialmente minha mãe, gostava muito do campo, dos Alpes, das serras e passávamos as férias na natureza. Tinha um certo gosto de viver na natureza e por isso hesitei na escolha entre ciências naturais e geografia. E no final, escolhi a geografia; de facto, comecei a estudar geografia por uma razão muito simples: as aulas principais da Universidade eram dadas no dia em que não havia ensino primário. Quando eu comecei a ensinar em uma escola primária eu tinha a quinta-feira disponível e era o dia em que davam aulas da geografia; assim, eu conheci a geografia, gostei imenso desde o princípio e, portanto, continuei na geografia. E foi assim, simplesmente. 
KS/JM: Quais foram os pensadores e as obras fundamentais que influenciaram sua formação acadêmica, em termos teóricos e metodológicos?

SD: Tive uma Professora, de letras e literatura, no Liceu, que foi uma Professora ótima, que nos abriu muito os horizontes. Nos fez conhecer não só a literatura clássica, mas também a literatura dos romances que saíam na altura. Depois, tive os Professores da Sorbonne, já na Geografia. Eu trabalhei muito com o Professor que foi Diretor da minha tese, Georges Chabot; não era o Professor mais afamado. Quem era brilhante era o Diretor da Secção, este me irritava um bocadinho, porque era exatamente muito brilhante, mas não dava uma sensação de perfeita honestidade intelectual e eu era uma adolescente muito exigente. Tive muita sorte porque ele [Georges Chabot] me escolheu, junto com outros colegas, para fazer um trabalho de campo de alguns dias, nos conhecemos melhor e depois foi ele que dirigiu a minha tese, me acompanhou nas aulas, até que, mais tarde, nos tornámos colegas. Por exemplo, o meu marido, Professor Orlando [Ribeiro], dizia que Leite de Vasconcelos, um etnógrafo que o acompanhou enquanto aluno, mas fora do ensino, era um guia espiritual para ele. Eu não tive assim uma pessoa tão importante para mim, como o Leite foi para o Orlando, por exemplo. Eu tive bons Professores, tive depois colegas que me ensinaram muita coisa, nomeadamente quando estávamos a criar em Dakar uma Universidade. Isto era extremamente interessante, pois tínhamos que adaptar o ensino que tínhamos recebido, o ensino francês clássico, a uma realidade completamente nova, em um país com pouca informação. Tivemos que criar a geografia que íamos ensinar aos alunos, tínhamos que lhes mostrar como fazer a geografia de um país em que não havia quase nada escrito, e foi dessa maneira que fomos fazendo, pouco a pouco.

Quando eu cheguei cá [a Portugal], havia uma pessoa que dominava, de muito longe, a geografia portuguesa que era o Orlando Ribeiro, que é um caso muito especial (risos). 0 Orlando começava na altura, pela primeira vez, a ter discípulos depois do Ilídio do Amaral, o Jorge Gaspar, o António de Brum Ferreira, o Carlos Alberto Medeiros, a Carminda Cavaco, a Isabel Marques. Foi a primeira geração que começava ao mesmo tempo que eu cheguei. Era uma escola absolutamente dominada pelo Orlando, mas que estava em plena expansão. Eu cheguei nessa altura e tive que aprender Portugal porque eu conhecia muito pouco, mas fui, evidentemente, profundamente ajudada pelo Orlando que me levou imediatamente às excursões. Tanto ele quanto eu adorávamos trabalho de campo. Antes de casarmos, desde que nos conhecemos, começámos a correr Portugal e ele me mostrou tudo o que sabia do país, ao mesmo tempo que dizia "tu vais me ajudar a escrever A Geografia de Portugal", o grande sonho dele na altura. Ele já tinha escrito o primeiro livro "Portugal, o Mediterrâneo e o Atlântico", depois tinha escrito uma "Geografia de Portugal" rapidamente em português, que foi traduzida para espanhol e publicada, anos mais tarde, em quatro volumes. Mas ele considerava que estes eram trabalhos preliminares; ele queria mesmo escrever uma grande geografia de Portugal equilibrada, completa. E quando eu apareci, ele pensou que nós os dois poderíamos fazer isso, mas, ao mesmo tempo, eu estava mais especializada do que ele em geomorfologia e climatologia. Como o Orlando tinha muito boas relações com um militar, o Professor Armim Ferreira, Diretor do Serviço Meteorológico de Portugal, ele o incitou a publicar, de forma compilada em pequenos fascículos, o que se sabia na altura sobre o clima de cada região. Foi essa documentação que utilizei nos livros que escrevi na altura, sobre a temperatura, sobre a pluviosidade, etc. Quando eu cheguei, aqueles documentos já existiam e eu me apoiei neles para fazer uma espécie de interpretação sobre esse material. Como está a perceber, trabalhámos assim muito proximamente, completando-nos um ao outro, de uma maneira muito interessante. Ao mesmo tempo apareciam esses jovens, cada um com sua personalidade; por exemplo, o Jorge Gaspar, que tinha ido fazer um estágio na Suécia, estava interessado em estudar uma nova ideia sobre a importância das relações de uma cidade com sua área 
de influência, e escreveu a tese "A área de influência de Évora: sistema de relações e lugares centrais". Quer dizer, apareceram assim novas ideias que resultavam do fato do Orlando mandar os jovens estudar em várias Universidades e aprender novas técnicas. 0 núcleo de geografia na altura desenvolveu-se. Houve uma fase de crescimento muito rápido e de expansão e diversificação da geografia.

KS/JM: A senhora teve uma estadia de quase uma década (1957-1964) em África, o que resultou em muitas pesquisas, viagens e também experiências mais difíceis tendo que lidar com muitas carências. Por que a opção da senhora por aquele continente? E do ponto de vista pessoal, o que a experiência africana ensinou?

SD: Bom, como disse rapidamente, a minha mãe era já uma pessoa que gostava de viajar, evidentemente na altura não se ia tão longe e, aliás, isso já vinha do pai dela. 0 meu avô, que era um jovem francês do campo que tinha vindo com 12 anos trabalhar para Paris, possuía só o Ensino Primário, mas que muito rapidamente se apaixonou pela fotografia, de modo que herdámos dele uma coleção formidável de fotografia. Ele, a filha [a mãe de Suzanne Daveau] e a mulher também, minha avó, desde que tivessem dias livres, gostavam muito de ir até aos Alpes descobrir as paisagens magníficas. Eles não tinham muitas férias, mas quando tinham 8-10 dias viajavam e a nossa mãe nos criou com amor a descobrir paisagens, acampar; passávamos o verão fora de Paris, etc. Desde que a Guerra acabou, porque durante a Guerra não se podia sair de Paris, desde que foi possível viajar, comecei a querer sair de França. Eu era estudante na altura, o Touring Club de França organizou uma viagem para Hoggar, uma montanha no meio do Saara, onde vivem os tuaregues. E o Touring Club, pela primeira vez depois da Guerra, organizou uma viagem na altura da Páscoa para ir até esse lugar mítico. Inscrevi-me, fui e fiquei deslumbrada pelas paisagens do Saara. Voltei a Paris e fui falar com o Professor que dirigia minha tese, que era sobre a fronteira do Jura. Mas eu tinha que fazer outro trabalho, porque na altura eram precisos dois trabalhos de doutoramento, e até já tinha escolhido o tema: era sobre o vale de um pequeno rio perto em Paris porque era fácil como lugar. Só que a ida ao Saara me modificou, eu contei minhas aventuras da Páscoa, e disse ao Professor: "Olha, se eu pudesse fazer a tese sobre uma região destas seria formidável”. E ele respondeu: "Talvez não seja impossível, vou tentar lhe arranjar uma bolsa". E a verdade é que se mexeu e arranjou-me uma bolsa. Eu tinha colegas meus da mesma geração que tinham acabado de ser nomeados para lugares de investigação que foram criados nas várias colônias francesas da África Ocidental, e isso era um apoio. Resultado, fui a Dakar, dali consegui viajar com um colega senegalense, Amadou M’Bow, futuro Diretor da UNESCO, que era então encarregado de um trabalho sobre desenvolvimento rural e tinha um carro; enfim, fui estudar a escarpa do Bandiagara. Não tinha meios de transporte, cada vez que alguém circulava de carro eu aproveitava, eu pegava bicicletas emprestadas, eu era muito nova, não tinha medo de nada (risos) e fiz esse segundo trabalho. Voltei a França, escrevi os trabalhos, apresentei e correu bem tornei-me Doutora. Nessa altura, criou-se a Universidade de Dakar e o colega que era encarregado pela geografia ainda não era Doutor, ainda estava fazendo a tese. Como me conhecia do tempo em que estive em Dakar, me perguntou se eu estava interessada em ir para lá. Assim, ao invés de eu ir para uma cidadezinha de Província da França, fechada e adormecida, eu ia para África criar uma Universidade; era entusiasmante. E foi assim que eu fui para África em 1956 e fiquei até 1964, porque em 1965 eu já estava em Portugal. Foi tempo de eu ensinar, de ter alunos e aproveitei também para continuar a investigação e correr por vários lugares. Era uma altura em que se podia circular com perfeita segurança. Ainda funcionava uma estrutura administrativa herdada da colonização francesa, os africanos ainda tinham um certo receio da dita administração colonial mas, ao mesmo tempo, viam à sua frente muito próxima a independência e tudo corria numa certa euforia, numa esperança 
ingénua num futuro melhor. Em relação ao contato humano, estar em África foi o contato com uma sociedade diferente e muito interessante. Há certas coisas que se podem dizer, outras que não se podem dizer, as pessoas não têm exatamente a mesma reação. Por exemplo, chegando à Universidade com os alunos, eu estava habituada, sendo uma mulher e Professora, que eles me deixassem passar a porta, eu nem pensava, era instintivo. Na França, os homens deixam as mulheres passar, as mulheres não tinham muito papel na sociedade, mas quando se chegava à porta, o homem deixava passar a mulher e ali não. Entre os africanos, eram os homens que passavam a frente. Resultado, no começo, quando chegávamos à porta, nos esbarrávamos. É o tipo de coisa que a gente aprende rapidamente com os africanos senegaleses, do Mali, da África Ocidental que estavam lá reunidos em Dakar e isso era interessante porque eles próprios tinham formações muito diferentes, tinham línguas diferentes, o francês que dava uma unidade, e os hábitos também eram distintos. Essa Universidade de Dakar funcionava como um lugar de encontro de pessoas que tinham tido formações muito diferentes, o que era extremamente interessante, pois aprendemos todos a respeitar o outro. No princípio havia desencontros, mas bastava dizer "olha, nós nos entendemos e na minha terra é tal e tal, como é na sua terra? E todos explicavam". E depois a gente se entendia muito bem. Realmente, as relações humanas com os africanos foram ótimas, isso abre; é importante aprender a viver com pessoas com uma cultura diferente e, reciprocamente, a gente percebe o que é uma sociedade diferente. E afinal, quando cheguei a Portugal foi um pouco a mesma coisa, os portugueses são terrivelmente sensíveis e vivem com medo de serem desprezados. Isso deve ter mudado muito. Depois do 25 de abril muita coisa mudou, mas o Portugal que eu conheci, a maneira de viver me lembrava a sociedade que os meus pais me descreviam, está a ver? Os portugueses não tinham carros, eram pobres, a maneira de vestir era um pouco o que eu tinha visto nas fotografias que o meu avô mostrava, havia um desfasamento, hoje não há. A Europa vive de certa forma toda ao mesmo ritmo e veste-se da mesma maneira. E também havia coisas que se podiam dizer e outras que não se podiam dizer. [A Fernanda Alegria no livro sobre a senhora diz que essa forma humilde de lidar com as pessoas pode ser explicada pelo tempo que passou em África e pelo convívio com muitas culturas. O que a senhora acha?] (Risos) Penso que primeiro é da minha natureza, segundo acho que foi de na França ter menos hierarquia social do que no Portugal que eu conheci. E eu sou de uma classe social, como já lhe disse, popular, mas não o meu fundo [risos]... de tal maneira que, desde cedo, quando comecei em França a ter contatos com universitários, primeiro como aluna, mas sobretudo, quando comecei a entrar na Universidade como Assistente, antes de ser Professora, eu não gostei muito. Eu entrei na Universidade com muito respeito pelos universitários, eram sábios, respeitados, mas muitas vezes via-os com pequenas histórias não muito simpáticas e muito mesquinhas, e perdi rapidamente certos aspectos do meu respeito inicial. Tudo isso me deu, pouco a pouco, o sentido de tratar as pessoas individualmente e não em função de sua posição social... e é a minha natureza também, com certeza. Não me parece que a África tenha sido muito importante nisso, o que a África me deu realmente foi perceber que mesmo em sociedades muito diferentes, onde cada um tem sua organização e o seu sistema de valor, há respeito de qualquer modo. Evidentemente que antes de eu ir para a África, ainda em França, tinha a ideia, o preconceito, que os negros eram pessoas simpáticas, mas pouco inteligentes o que não é nada verdade. Eu tive alunos negros uns excelentes, outros médios e outros piores, exatamente como em todo lugar do mundo.

KS/JM: A senhora, enquanto Professora de geografia física, acompanhou de perto as investigações que se faziam em Portugal, tanto pelos alunos de doutoramento quanto pelos pesquisadores estrangeiros que vinham trabalhar no país, incluindo-se aqui o desenvolvimento de áreas de estudos pioneiras como: o estudo das formas de relevo submersas, estudo sobre o clima com propósitos práticos, etc. Também trouxe para Portugal métodos de pesquisas desconhecidos até então como os blocos diagramas, o perfil 
projetado, fotografia aérea e teledetecção. Como foi ser mulher e investigadora jovem, mas com larga experiência, em uma sociedade dominada por homens no Portugal de 1970?

SD: Nisso Portugal não estava em nada atrasado em relação a França. Havia já na Faculdade de Letras uma Professora de História, Virgínia Rau, que até tinha sido a Diretora da Faculdade, muito antes disso acontecer em Paris. Então, nisso da progressão das mulheres na Universidade, Portugal não estava atrasado, estava na média europeia e eu diria um pouco a frente da França. Por quê? Eu não sei, talvez um pouco o acaso. Porque havia muito pouca gente na Universidade, havia duas Universidades em Portugal na altura, Coimbra e Lisboa, e ainda uma que não tinha geografia, uma vez que no Porto a geografia foi criada mais tarde. Os Professores universitários eram poucos e entre eles já se contavam algumas mulheres. Havia esta professora na História, outras assistentes na Faculdade de Letras, em Ciências também havia, era uma boa média européia. Eu não tive que lutar. 0 Orlando tinha nessa altura, como já lhe disse, alguns bons alunos e alunas, a quem ajudou de forma equivalente; nisso, o Orlando nunca fez nenhuma diferença. Não era o caso de toda gente, mas na parte que lhe coube, ele ajudou as raparigas que queriam estudar exatamente como ajudou os rapazes.

KS/JM: As especializações temáticas parecem afastar cada vez mais a geografia da idéia de unicidade, levando os geógrafos a recorrentes debates sobre a divisão entre a geografia física e a geografia humana. o que a senhora pensa a esse respeito?

SD: Isso apareceu depois da minha chegada cá. É a geração seguinte que começa a se especializar. É inevitável quando uma ciência se desenvolve que apareçam as especializações. Quando a gente está a preparar uma tese sobre um assunto é evidente que durante anos está se especializando no tema que se está a estudar. Está-se a fazer um estudo e se deseja que esse estudo represente um progresso para a ciência e que não seja só uma aplicação de conceitos que já estão feitos. Para isso é preciso se especializar, é evidente. Eu fiz uma tese principal sobre um tema que havia sido muito pouco estudado, o papel de uma fronteira na organização do espaço. Quando fui para África fazer o trabalho, podia ter escolhido um tema mais geral, mas escolhi geomorfologia que era um tema na moda na altura e, também, porque não sabendo a língua do país era umas das coisas que podia fazer: olhar a paisagem. Existiam alguns mapas muito fracos na altura, mas só de ver a paisagem e fazer fotografias podia se fazer o estudo. Já para fazer um trabalho de climatologia era preciso que durante anos tivesse havido registos, coisa que não acontecia. Para fazer um trabalho de geografia botânica era preciso ter uma formação que eu não possuía, está a ver? No pouco tempo disponível, a geomorfologia era das poucas coisas que se podia fazer e foi em boa parte por isso que a escolhi [risos]. Não necessitava que se tivesse compilado anos e anos de informação estatística. E se eu tivesse optado por fazer um trabalho de geografia humana, como eu não sabia falar as línguas locais, a minha interpretação teria sido muito superficial. No pouco tempo, era das poucas coisas que se podia fazer e foi um pouco por isso que eu escolhi fazer geomorfologia. [E sobre a profunda discussão sobre a separação da geografia física $e$ humana?] Quando cheguei cá, os mais jovens já começavam a fazer tese ou de física ou de humana. Começava a haver uma separação. A nível de doutoramento não acho nada escandaloso, até eu fiz um trabalho de humana e outro de física. Agora eu penso que um geógrafo deve dominar, não dominar a fundo porque é impossível, mas ter uma formação básica tão larga quanto possível. Afinal, o que é específico da geografia são as relações do homem com a superfície da terra. Estudar o homem... há muitas especialidades que estudam o homem e a terra também. 0 que é específico da geografia, a meu ver, é que nós tentamos perceber as relações do homem com o espaço, chamando aqui o espaço de superfície terrestre. Isso para mim é a parte mais interessante da geografia; e cada especialização tem que ser partilhada com especialistas de outras ciências. Eu trabalhei muito desde que estou em 
Portugal com geólogos, porque o estudo do tempo relativamente mais recente da superfície terrestre é o que modela a aparência atual; quer dizer, o geólogo está muito próximo do geógrafo, ele nos diz como era antes e nós ajudamos porque temos capacidade para ler as paisagens agora e isso ajuda-os. 0 geógrafo, na minha forma de ver, não deve ser geomorfólogo ou sociólogo do tal ou tal aspecto social. Não deve ter uma cultura específica muito profunda, talvez, mas suficiente para ser capaz de sentir as relações existentes entre a sociedade humana e o espaço onde vive. Bom, que a geografia seja útil para planificar, perfeitamente de acordo, mas que seja uma geografia enraizada no espaço e não só na sociedade.

KS/JM: Os trabalhos desenvolvidos pela Professora Suzanne Daveau extrapolam o campo da geografia fazendo com que não só geógrafos pudessem beneficiar do seu saber, tendo a professora colaborado com historiadores, arqueólogos, geólogos, botânicos, etc, inclusive levando o notável historiador José Mattoso a reconhecer que foi com a incursão da Professora na história que o campo do saber da geografia histórica ganhou clareza e rigor. Como a senhora enxerga a importância dos geógrafos terem o "espírito aberto" para o diálogo com outras ciências?

SD: Eu acho quanto mais aberto melhor. Aprendemos muito com pessoas que vêem a paisagem de um jeito diferente, se somos capazes de comunicar e transmitir a maneira como vemos este espaço estamos a enriquecer o outro e ao mesmo tempo a nos enriquecer. E quanto mais contactos com pessoas que têm uma visão diferente da nossa mais progredimos. Nada pior que ficar fechado na sua própria visão.

KS/JM: Pensando em todos os trabalhos realizados pela senhora, em qual deles mais se realizou, qual deu mais prazer ao ser executado?

SD: Foram tantos e todos tive prazer em fazer (risos); por isso é muito difícil responder a isso. Mas deixe eu pensar um pouco. Eu gostei muito de trabalhar com jovens, cada um poderia se desenvolver, cada um em sua direção, de sentir que eles estavam agradecidos por eu ter ajudado. Agora, queria um trabalho meu? Uma publicação minha? Estes últimos livros sobre o Orlando, essa última obra que está aqui [Mestres, Colegas, Discípulos de Orlando Ribeiro, vols. 1 e 2], deu muito prazer a fazer, porque foi uma maneira de viver com ele depois da sua morte. Há muito tempo que trabalho com o Orlando, desde cedo ele teve problemas de saúde graves e por isso desde cedo que o ajudei a publicar, especialmente "A geografia de Portugal" em 4 volumes, aí eu ajudei muito. 0 tempo passou, Orlando morreu, a Gulbenkian sobreviveu e um belo dia eles me disseram que queriam fazer mais uma edição do livro "Mediterrâneo. Ambiente e Tradição", que já tinha tido duas edições. E então, eles me mostraram a edição que estavam a preparar. Na primeira edição tínhamos posto fotografias a cor (era o começo das fotografias a cor), e não estavam muito bem reproduzidas. Considerando isto, disse-lhes "Já que estão dispostos a publicar, é melhor reconsiderar a ilustração". Assim, fiz ilustrações muito mais abundantes e melhores, e saiu a nova edição que está agora esgotada e já me disseram que iam reeditar. [Então, essas publicações sobre o Orlando Ribeiro são as que mais têm realizado a senhora?] É evidente que para essas reedições eu fiz o trabalho de rever, fazer introduções, escolher fotografias, etc. Para fazer isso, falei com um responsável na Gulbenkian que conhecia muito bem o Orlando e que me disse que, além das obras geográficas dele, preparasse um livro onde reunisse os artigos que ele escreveu sobre outros geógrafos. Achei interessante e disse que ia pensar. Comecei, então, a recolher os artigos do Orlando e estes eram tantos que não cabiam em um livro. Aí, eu propus à Gulbenkian fazer um primeiro livro, onde reunia tudo que tinha a ver com a Universidade, a ciência em geral e mesmo a cidadania, e deixar de lado tudo que era biográfico ou bibliográfico. Preparei, então, este livro que deu muito trabalho e muito prazer ao mesmo tempo e foi publicado em 2013. Isso mostra 
que desde há uma dezena de anos, uma grande parte da minha atividade foi retomar as obras do Orlando, reestudá-las e fazer todo o trabalho de edição. Até há poucos meses foi a minha grande ocupação.

KS/JM: Como se vê, a senhora tem se dedicado muito à divulgação e publicação das obras do Professor Orlando Ribeiro. E a Professora pensa em dar visibilidade às obras de Suzanne Daveau?

SD: Tenho muito gosto disso. Por um lado já percebeu que gostei muito do meu marido (risos) e, além disso, penso que a obra dele é muito importante. É com muito prazer que renasce este interesse, depois de anos em que ficou um pouco esquecido, como é habitual durante certo tempo, quando uma pessoa morre. Depois, vem nova geração. 0 interesse renasce e os livros voltam a vender-se. Estou muito satisfeita em ver que o meu trabalho foi útil. Agora o meu trabalho sobre as obras do Orlando está acabando e, para mim, é um momento que não é fácil porque significa uma espécie de ruptura de uma rotina de anos na maneira de viver, na maneira de trabalhar... E na minha idade, readaptar-se a uma outra coisa não é fácil. Mas o que estou a fazer é o retorno à minha obra, tentar classificá-la. Isso é o que eu estou a fazer com uma amiga. Está a ver ali? [apontando para uma estante com pastas classificadoras por décadas] É uma coleção dos meus artigos, com cópias quase completas. Estamos a preparar dois exemplares, um que ficará pronto agora e o outro que irá um dia para a Biblioteca Nacional ou para o Centro de Estudos Geográficos, ainda não sei. O que estamos a pensar é completar e corrigir a lista das minhas obras que se publicou na Finisterra. Isto irá para a Internet, mas já não sou eu que o farei; serão os meus amigos a tratar disso e eu ajudarei no que eu puder. Outra coisa que tenho aqui, que estou a fazer com a minha irmã e uma amiga cineasta, são as minhas fotografias as quais estamos tentando colocar em ordem, mas faltam muitas para acrescentar. Serão usadas em um filme que estão a fazer sobre a minha vida. Tenho ido a Paris para ajudar a contar essa história.

\section{KS/JM: A Professora Suzanne Daveau trabalhou com geógrafos brasileiros? Quais?}

SD: Sim. Conheci e convivi com bastantes colegas brasileiros ou de outras nacionalidades, mas brasileiros de coração, como Pierre Deffontaines, Pierre Monbeig, Jean Demangeot, Karl Troll, Pierre Dansereau e Jan Bitoun, tanto em Lisboa como na África ou durante as duas visitas que fiz ao Brasil, conhecendo então o Rio, a Bahia e o Ceará durante a minha primeira estadia, em 1965, e visitando Belo Horizonte, Ouro Preto, Brasília e o Recife na segunda, em 1998. Na África, tinha tido a visita, em Dakar, de Milton Santos e trabalhei na Mauritânia com Regina Mousinho. Em Lisboa, tivemos muitas visitas, tanto de jovens estudantes, como Auxiliadora, Regina, o historiador Johildo, Aldo Paviani, como de velhos amigos do meu marido, como Orlando Valverde, Hilgard Sternberg, Aziz Ab'Saber, Dora Romariz, Nilo e Alda Bernardes. Estes encontros eram sempre ocasião de alegre convívio e de apaixonante trabalho de campo.

KS/JM: Que mensagem a senhora deixaria para os jovens investigadores e Professores que escolhem hoje a geografia, ciência que a senhora ajudou a construir, como forma de interpretar o mundo?

SD: Fico encantada quando as pessoas escolhem a geografia. Agora a dificuldade que eu tenho atualmente é de perceber como se pode fazer geografia tendo uma formação unicamente humana ou unicamente física. A meu ver, para ser geógrafo tem que se ter uma formação que junta essas duas componentes. Mas como está a perceber, há muitos anos que eu tenho muito pouco contato com a vida universitária. Afinal, eu vivo aqui isolada. Não completamente isolada porque tenho amigos que cá vêm, mas não vivo diariamente no Centro, pelo que tenho perfeita consciência que as ideias que tenho 
atualmente da maneira como praticar, como ensinar a geografia, são pouco desenvolvidas. Mas é bom ter os contatos que ainda possuo e fazer o trabalho de revisão dos resumos da Finisterra, porque assim me permito ver o que se publica. Mas tenho consciência que minhas ideias atualmente não são muito profundas porque vivo fora desse mundo. Mas eu penso que a geografia, aliás, como todas as outras ciências, caiu em um excesso de especialização, mas não é só a geografia. Eu vejo meus sobrinhos, bisnetos que tem essas mesmas coisas. Eles nem conseguem falar uns com os outros porque cada um tem uma especialização muito estreita. Eu penso que a Ciência e a evolução humana é uma coisa que vai por oscilação ou, talvez melhor, por espiral... Daqui a um certo tempo volta ao ponto de partida, ou melhor, para um ponto relativamente perto do antigo ponto de partida, modifica-se passando perto ou longe de uma situação anterior. 0 ideal seria que todos tivessem também uma formação dentro de uma cultura geral; é só isso que posso dizer. Mas são os jovens que fazem o futuro da ciência. Eu fico muito contente quando vejo jovens interessados, vivos, cheios de interesse. Para mim é o maior prazer que posso ter. 